\title{
Correction to: The Reduction Method of a Stray Load Loss of Distribution Transformer on the Bushing Flange Plate with STS
}

\author{
Sang-Hyun Kim ${ }^{1} \cdot$ Kyu-Jin Jung ${ }^{1} \cdot$ Young-Joo Kim ${ }^{2} \cdot$ Bum-In Shin $^{3} \cdot$ Hyang-Beom Lee ${ }^{1}$
}

Published online: 23 October 2019

(c) The Korean Institute of Electrical Engineers 2019

\section{Correction to: Journal of Electrical Engineering \& Technology (2019) 14:1607-1613 \\ https://doi.org/10.1007/s42835-019-00145-6}

Due to an unfortunate oversight the author name of JungKyu Jin has been misspelt. It should be read: Kyu-Jin Jung. The authors apologise for the mistake.

Publisher's Note Springer Nature remains neutral with regard to jurisdictional claims in published maps and institutional affiliations.

The original article can be found online at https://doi.org/10.1007/ s42835-019-00145-6.

Hyang-Beom Lee

hyang@ssu.ac.kr

Sang-Hyun Kim

comemom@naver.com

Kyu-Jin Jung

wjdrbwls2@gmail.com

Young-Joo Kim

babotihg@gamil.com

Bum-In Shin

sbi5356@sanil.co.kr

1 Department of Electrical Engineering, Soongsil University,

Seoul, South Korea

2 Department of Mechanical Engineering, Busan National

University, Busan, South Korea

3 Sanil Electric Co., LTD, Ansan, South Korea 